\title{
The Epidemiology of HIV/AIDS in Anguilla from 1988 to 2011
}

\author{
Chuku Okorie ${ }^{1}$, Aleksandra Marinkovic ${ }^{2}$, Lorena Likaj ${ }^{2}$, Oladapo Ayodele ${ }^{2}$, Abu Fahad Abbasi ${ }^{2}$, Jessica \\ Gosse $^{3}$, Sadaf Younis ${ }^{3}$, Jasmine Mangat ${ }^{3}$ and Adekunle Sanyaolu ${ }^{4 *}$ \\ ${ }^{1}$ Essex County College, Newark, New Jersey, USA \\ ${ }^{2}$ Saint James School of Medicine, Anguilla BWI
}

${ }^{3}$ All Saints University School of Medicine, Saint Vincent and the Grenadines

${ }^{4}$ Federal Ministry of Health Abuja, Nigeria

*Corresponding author: Adekunle Sanyaolu, Federal Ministry of Health, Abuja, Nigeria

\begin{tabular}{|c|}
\hline ARTICLE INFO \\
\hline Received: 蔧 February 06, 2020 \\
\hline Published: 豐 February 18, 2020 \\
\hline
\end{tabular}

Citation: Chuku Okorie, Aleksandra Marinkovic, Lorena Likaj, Oladapo Ayodele, Abu Fahad Abbasi, Jessica Gosse, Sadaf Younis, Jasmine Mangat, Adekunle Sanyaolu. The Epidemiology of HIV/AIDS in Anguilla from 1988 to 2011. Biomed J Sci \& Tech Res 25(4)-2020. BJSTR. MS.ID.004238.

Keywords: Human immunodeficiency virus (HIV); Acquired immune deficiency syndrome (AIDS); Antiretroviral treatment (ARVT); Anguilla; Caribbean

\begin{abstract}
This study was carried out on the Caribbean Island of Anguilla for the purpose of analyzing surveillance data related to the epidemiology of HIV infection in Anguilla from 1988 to 2011. We retrieved data from the National AIDS Programme office for research purpose. Data on HIV/AIDS in Anguilla were retrieved from 1988 to 2011 and analyzed with particular emphasis on the year 2011. The retrieved data provided key information on new cases, deaths, and treatment of existing cases. Result analysis shows that by December 31, 2011, the cumulative number of all HIV cases diagnosed since the surveillance started in 1988 was 42. Males accounted for 23 (54.8\%), while females accounted for $19(45.2 \%)$ of the diagnosed cases. There were 17 cases comprising 12 males $(70.5 \%)$ and 5 females $(29.5 \%)$, HIV-related deaths within the same period. No cases of AIDS were reported in the study period. The year with the highest number of HIV diagnosis was 1996, with 7 confirmed new cases. HIV prevalence in Anguilla is estimated to be $0.19 \%$. The number of tests conducted in 2008 holds steadfast as the highest in the 4 consecutive years from 2008 to 2011. There were 9 clients that received treatment and care from the Clinical Care Coordinator within the period under review. Data provided in this study shows a gradual decline in the incidence of HIV infection in Anguilla since it was first diagnosed in 1988. This is attributable to public awareness, surveillance, and access to antiretroviral treatment (ARVT).
\end{abstract}

Abbreviations: HIV: Human Immunodeficiency Virus; AIDS: Acquired Immune Deficiency Syndrome; ARVT: Antiretroviral Treatment; CAREC: Caribbean Regional; WHO: World Health Organization; HAART: Highly Active Antiretroviral Therapy; STI's: Sexually Transmitted Infections; TB: Tuberculosis: UNAIDS: Joint United Nations Programme on HIV/AIDS

\section{Introduction}

Similar to the rest of the world, HIV-1 is the most commonly seen virus in the Caribbean [1]. In fact, no infections with HIV-2 have ever been documented in the Caribbean [1]. The Caribbean has the second-highest HIV prevalence rate in the world, following Eastern and Southern Africa (6.8\%) [2]. UNAIDS (2018) informs us that the annual number of new HIV infections diagnosed in adults has decreased by approximately 18\% from 2010 to 2017 [3]. In 2007, the estimated prevalence of HIV infection in the Caribbean was approximately $1.6 \%$ [4]. The prevalence rate has since decreased to $1.2 \%$ [2]. As of 2017, 310,000 people were living with HIV in the Caribbean [2], a decrease from the 330,000 people living with HIV in the Caribbean in 2005 [4]. There were 1,500 new HIV infections diagnosed in the Caribbean in 2017 [2], whereas in 2005, roughly 37,000 people were diagnosed with HIV [4]. Haiti alone accounts for about half of all new HIV infections [3]. Of all Caribbean HIV infections, roughly $70 \%$ were recorded on the island of Hispaniola (Haiti and Dominican Republic), followed by Jamaica, then Trinidad and Tobago [1]. HIV prevalence rates vary among 
the Caribbean countries with the Bahamas rate at 3\% and Haiti, Trinidad and Tobago greater than or equal to $2 \%$, while Cuba's rate is less than $0.2 \%$ [5]. According to Avert (2019), there were 10,000 AIDS-related deaths in the Caribbean in 2017 [2]. Deaths from AIDS-related illness decreased by 23\% between 2010 and 2017 [3]. HIV related disease is the leading cause of mortality in Caribbean people 25 to 44 years of age [1]. Of all AIDS-related deaths, $87 \%$ occurred in the Dominican Republic, Haiti and Jamaica [3].

The Caribbean is experiencing a concentrated HIV epidemic, which refers to the idea that HIV prevalence is low in the general population, but is much higher among certain groups of individuals [2]. These groups include men who have sex with men, transgender women [2], commercial sex workers, drug users [5], tuberculosis (TB) patients, the homeless population [1] and prisoners [6]. Men who have sex with men accounted for a quarter of new HIV infections in the Caribbean in 2017 [3]. Heterosexual transmission is implicated in approximately $60 \%$ to $80 \%$ of cases of HIV infection in the Caribbean, with homosexual or bisexual transmission accounting for $10 \%$ to $15 \%$, and mother-to-child transmission for $6 \%$ to $10 \%$ [1]. National HIV programs have made progress in providing HIV/AIDS treatment, reducing AIDS-related death rates and decreasing HIV mother-to-child transmission [5]. Several Caribbean countries have eliminated mother-to-child transmission of HIV: Anguilla, Antigua and Barbuda, Bermuda, the Cayman Islands, Cuba, Montserrat, Saint Kitts and Nevis [3]. In 2017, the rate of mother-to-child transmission in the Caribbean was $13 \%$, significantly lower than a rate of over $18 \%$ in 2010 [2]. As a result, HIV infection in Caribbean children, aged 0 to 14, fell from 2,300 cases in 2010 to 1,100 cases in 2017 [2]. Awareness of HIV diagnosis has increased in the Caribbean from 66\% in 2016 to $73 \%$ in 2017 [2]. Currently, 58\% of adults are receiving antiretroviral treatment [ARVT] [2], compared to 2005, when $23 \%$ of people in need of ARVT were receiving treatment [4].

The beneficial effects of increased awareness and access to ARVT are evident when observing the decreased number of annual deaths attributable to AIDS, by 85\% between 2001 and 2006 [6]. The estimated number of people living with HIV who achieved viral suppression increased from 37\% in 2016 to $40 \%$ in 2017 [3]. The first case of HIV diagnosed in Anguilla was in 1988. Since then the Pathology Department of the Princess Alexandra Hospital Anguilla, has carefully tested and confirmed all HIV cases. Comprehensive reports of these cases are sent to the Caribbean Regional (CAREC) headquarters. In Anguilla cases are captured through various testing routes such as voluntary testing, blood, Provider Initiated Testing, and counseling and testing for antenatal clients, clinical investigations, and insurance and needle stick injury cases. Results are electronically sent to the Health Information Unit of Ministry of Health, Anguilla on a monthly basis, where they are collated, analyzed, compiled and included in the annual statistical report, which is then disseminated to all the stakeholders. For this study, we retrieved data from the National AIDS Programme office of the Ministry of Health and Social Development for the purpose of analyzing surveillance data related to the epidemiology of HIV infection in the Caribbean country of Anguilla from 1988 to 2011. This study provides a detailed account of the epidemiologic findings on HIV/AIDS in Anguilla from 1988 to 2011, with particular emphasis on the year 2011. It provides key information on the new cases, deaths, and treatment of existing cases.

\section{Methodology}

\section{Surveillance and Case Definitions}

HIV Case Definition: An HIV case, according to Anguilla's definition and requirements of the infection, is defined as a person with an HIV infection, irrespective of the clinical stage confirmed by laboratory criteria. HIV case reporting in Anguilla follows the World Health Organization (WHO) guidelines for adults, adolescents, and children over 18 months of age. The criteria for HIV infection in Anguilla are as follows:

a. "A positive HIV antibody test (rapid or laboratory-based enzyme immunoassay), confirmed by a second HIV antibody test (rapid or laboratory-based enzyme immunoassay) relying on different antigens or different operating characteristics than the initial test."

b. Other criteria for ruling-in the infection: "A positive virology test for HIV or its components (HIV-RNA or HIV-DNA or ultrasensitive HIV p24 antigen), confirmed by a second virology test obtained from a separate determination."

AIDS Case Definition: As the infection progresses, an AIDS case is defined as a person with confirmed HIV infection whose CD4 count falls below 200 cells per $\mathrm{mm}^{3}$.

HIV Related Mortality: For the study, the death of anyone diagnosed previously with HIV, irrespective of the cause, is considered an HIV-related death. Deaths are tracked through the Anguilla hospital admissions and other national deaths that are confirmed with the judiciary.

\section{Data Management / Analysis}

Data Gathering and Management: For every person newly diagnosed with HIV, the Laboratory Manager generates a Laboratory Tracking Form which is then sent to the National AIDS Programme. Multiple indicators are collected from the patient; data is also sent via the monthly serology form, which confirms the accuracy of HIV reporting system. Data are managed through a number of excel spreadsheets. Hard copies for each period are printed and kept in a ring binder for easy reference or research purposes.

Data Retrieval and Analysis: For this study, we retrieved data from the National AIDS Programme office for research purposes. Data on HIV/AIDS in Anguilla were retrieved from 1988 to 2011 and analyzed with particular emphasis on the year 2011. The retrieved data provided key information on new cases, deaths, and treatment of existing cases. Furthermore, an electronic literature 
review search was performed on PubMed, Google Scholar, and Medline Plus. The search was limited to peer-reviewed articles published from January 1, 2006, until 2019. The articles were selected if it included keywords such as human immunodeficiency virus (HIV), acquired immune deficiency syndrome (AIDS), and epidemiology in Anguilla and the Caribbean. Articles were then reviewed and included based on the applicability to the topic. Approval for the study was obtained from the Ministry of Health, Anguilla.

\section{Result}

\section{Trends in HIV epidemic from 1988 - 2011 in Anguilla}

The first case of HIV/AIDS was reported in Anguilla in 1988. Statistics show that by December 31, 2011, the cumulative number of all HIV cases diagnosed since the surveillance started in 1988 was 42. Males accounted for 23 (54.8\%), while women accounted for 19 $(45.2 \%)$ of the diagnosed cases. There were 17 cases comprising 12 males (70.5\%) and 5 females (29.5\%), HIV-related deaths within the same period. There were no cases of AIDS reported in Anguilla from 1988 to 2011. The cumulative number of HIV cases diagnosed, deaths related to HIV and persons living with HIV are displayed in Figure 1. In the year 1996, the number of newly diagnosed HIV cases peaked with 7 new cases. More females were diagnosed with HIV than males in the ratio of 4:3, respectively. Both 2002 and 2010 showed an increase in the newly diagnosed cases of HIV with all the 4 new positive cases being males. However, 2 out of the 4 cases in 2010 were diagnosed outside the Anguillan public health institutions. The year with the highest number of HIV diagnosis was 1996 with 7 confirmed new cases. Since this peak, there has been a gradual downward trend in the number of people diagnosed with HIV in Anguilla annually. The new HIV cases for the period between 1988 and 2011 disaggregated by gender are illustrated in Figure 2.

\section{Data from 1988 to 2011}

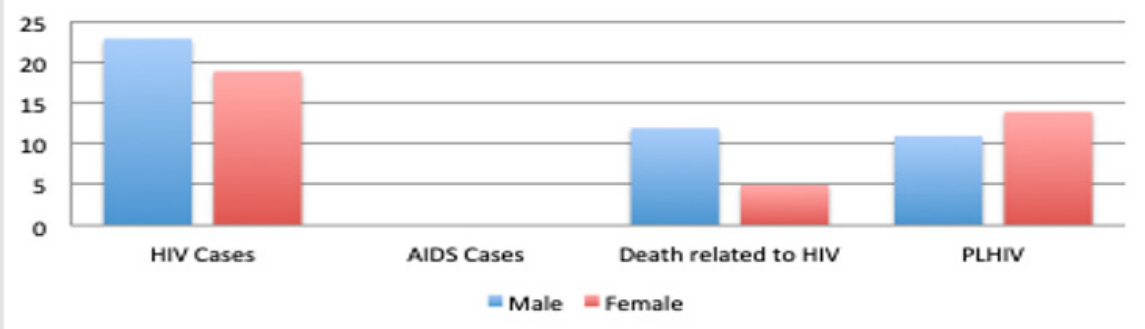

Figure 1: Cumulative HIV cases, AIDS cases, and deaths related to HIV, and people living with HIV from 1988 to 2011. Source: Pathology Department Princess Alexandra Hospital, 2011.

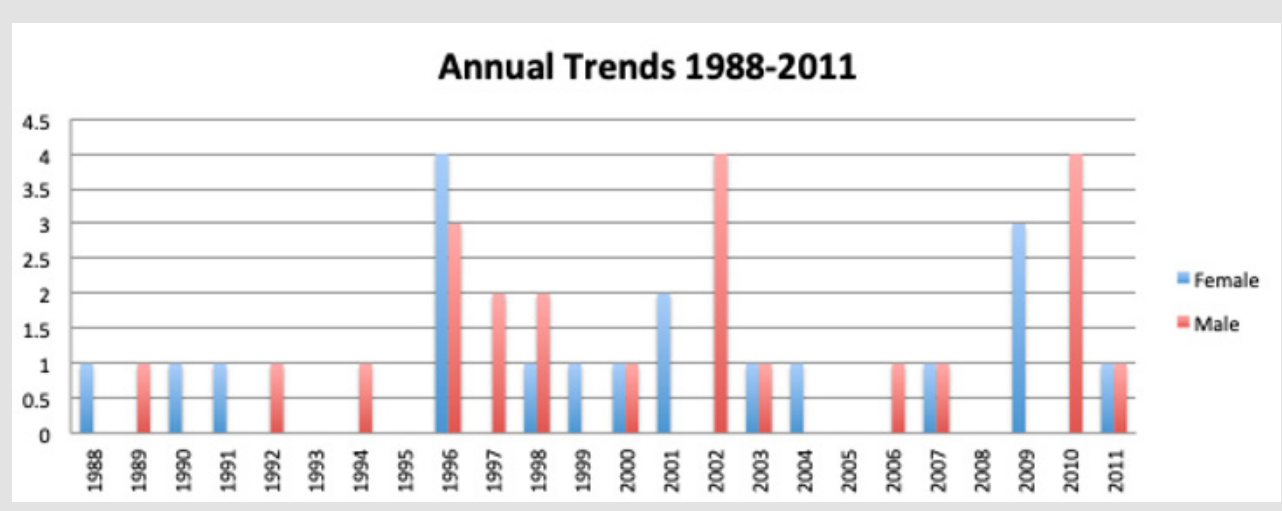

Figure 2: Annual Trends of Newly reported HIV Cases, 1988 - 2011. Source: Pathology Department Princess Alexandra Hospital, 2011.

\section{Trends in new HIV cases 1988-2011}

In 2011, 2 persons were newly diagnosed with HIV in Anguilla. The new cases were proportionately distributed between the two sexes, one male $(50 \%)$ and one female (50\%). Hence, males accounted for $50 \%$ and females $50 \%$ of the new HIV cases in 2011. The median age of newly diagnosed HIV cases for males was 22 years and that of females was 17 years. This data is illustrated in
Table 1. HIV prevalence in Anguilla in 2011 was determined based on diagnosed cases of HIV that were not deceased at the end of 2011, as well as the total population at the end of 2011. The population of Anguilla as of December 31, 2011, using the data from the Statistics Department of Anguilla was 13,037. The population distribution according to the sexes was females 6,568 (50.4\%) and males 6,469 (49.6\%). Using this methodology, the prevalence of HIV in 
Anguilla is estimated to be $0.19 \%$. The female population had a higher prevalence of HIV than the male population in Anguilla in 2011, which was $0.21 \%$ and $0.17 \%$, respectively. This methodology does not take into account the undiagnosed cases; neither does it exclude those lost to follow up. The assumption is that all the HIV cases were alive until reported dead. The table below shows the prevalence of HIV in Anguilla as of 2011. This data is presented in Table 2.

Table 1: Total new HIV cases by age and sex in 2011. Source: Pathology Department Princess Alexandra Hospital, 2011.

\begin{tabular}{|c|c|c|c|c|}
\hline \multicolumn{2}{|c|}{ Male } & Female & N & Total \\
\hline \multicolumn{2}{|c|}{} & & 1 & 1 \\
\hline $15-19$ & 0 & 1 & 1 & 50.0 \\
\hline $20-24$ & 1 & 1 & 2 & 50.0 \\
\hline Total & 1 & 17 & 0 & 100.0 \\
\hline Median Age & 22 & 1 & \\
\hline
\end{tabular}

Table 2: Prevalence of HIV as of December 31, 2011 in Anguilla. Source: Statistics Department of Anguilla.

\begin{tabular}{|c|c|c|c|}
\hline Sex & PLHIV at the End of 2011 & $\begin{array}{c}\text { Population in Anguilla at the End } \\
\text { of 2011 }\end{array}$ & $\begin{array}{c}\text { HIV Prevalence at the End of } \\
\text { 2011 (\%) }\end{array}$ \\
\hline Male & 11 & 6,469 & 0.17 \\
\hline Female & 14 & 6,568 & 0.21 \\
\hline Total & 25 & 13,037 & 0.19 \\
\hline
\end{tabular}

\section{Laboratory testing 1988 - 2011 vs. 2011}

In 2011, there were 901 HIV laboratory tests conducted. There were 2 confirmed positive cases of HIV and 899 negative results. There were more females, 455 , tested than males, 446. Compared to the number of laboratory tests conducted in 2009 (856), there was an increased number of HIV tests conducted in 2010 and 2011 However, 2009 saw a sharp drop in the number of tests performed in the previous year of 2008 (925). The number of tests conducted in 2008 holds steadfast as the highest in those 4 consecutive years. This is shown in Figure 3.

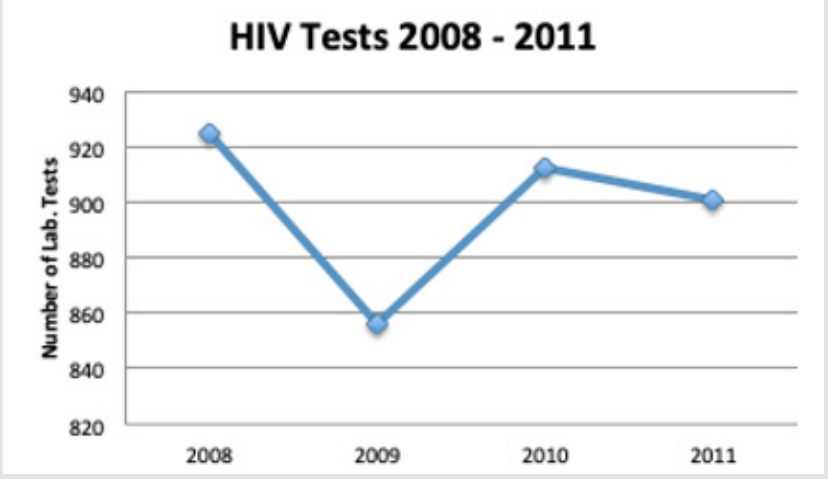

Figure 3: HIV tests done annually from the beginning of 2008 to end of 2011.

\section{Patients' status, treatment, and care data}

The Clinical Care Coordinator, who is a physician in private practice in Anguilla, started the medical care program for HIV+ individuals in 2003. The data presented for individuals in treatment and care begins from 2003 until December 31, 2011. There were 9 clients that received treatment and care from the Clinical Care Coordinator within the period under review. The care and treatment of 6 of the mentioned 9 patients were managed via the National AIDS Programme of the Ministry of Health and Social Development. The other 3 were self-sponsored. Of the 9 patients, 7 were on highly active antiretroviral therapy (HAART). There are more males, 6 (66.7\%), registered in the treatment and care program than females, $3(33.3 \%)$. Of all persons receiving treatment from the Clinical Care Coordinator, $44 \%$ fall within the age group $40-44$ years. Males and females were equally represented in this age group in the ratio of 1:1, respectively. This data is illustrated in Table 3 and Figure 4. On average, these 9 patients visited the Clinical Care Coordinator twice a year and their CD4 and viral load blood test were done on a quarterly basis. However, 5 (55.6\%) of these patients were at an advanced stage of the disease with a CD4 count of less than 350 cells per $\mathrm{mm}^{3}$. This is illustrated in Table 4. At the start of treatment, 7 patients were on HAART. However, 4 (57.1\%) out of the 7 patients were still on first line therapy and 3 (42.9\%) out of the 7 were on second line therapy. Table 5 illustrates the information of the 9 patients under the care of the Clinical Care Coordinator.

Table 3: Individuals receiving HIV - related care from 2003 to 2011. Source: Clinical Care Coordinator- Atlantic Star Medical Center.

\begin{tabular}{|c|c|c|c|c|}
\hline \multicolumn{2}{|c|}{ Male } & Female & N & Total \\
\hline \multicolumn{2}{|c|}{ Age Group (Years) } & & 1 & 11.1 \\
\hline $20-24$ & 1 & 0 & 0 & 0.0 \\
\hline $25-29$ & 0 & 0 & 0 & \\
\hline
\end{tabular}




\begin{tabular}{|c|c|c|c|c|}
\hline $30-34$ & 0 & 1 & 1 & 1 \\
\hline $35-39$ & 1 & 0 & 4 & 11.1 \\
\hline $40-44$ & 2 & 2 & 1 & 44.4 \\
\hline $45-49$ & 1 & 0 & 0 & 11.1 \\
\hline $50-54$ & 0 & 0 & 1 & 11.1 \\
\hline $55+59$ & 1 & 0 & 9 & 100.0 \\
\hline Total & 6 & 3 & & \\
\hline
\end{tabular}

Table 4: Patients receiving care and treatment according to the WHO immunological classification of HIV related disease. Source: Clinical Care Coordinator- Atlantic Star Medical Center.

\begin{tabular}{|c|c|c|c|}
\hline $\begin{array}{l}\text { WHO HIV- Associated Immunological } \\
\text { Classifications }\end{array}$ & CD4 Level (Cells/MM') & Number of Patients & Percentage \\
\hline Severe & $<200$ & 0 & 0.0 \\
\hline Advanced & $200-349$ & 5 & 55.6 \\
\hline Mild & $350-499$ & 2 & 22.2 \\
\hline \multirow[t]{2}{*}{ None or not Significant } & $500+$ & 2 & 22.2 \\
\hline & Total & 9 & \\
\hline
\end{tabular}

Table 5: Data for patients receiving care and treatment from the Clinical Care Coordinator.

\begin{tabular}{|c|c|c|c|c|c|c|}
\hline Client & Age & Sex & Beginning Date of Care & Initial CD4 Level & HAART & CD4 in 2011 \\
\hline 1 & 43 & Male & 03-06-2005 & 178 & Yes* & 157 \\
\hline 2 & 57 & Male & 03-21-2006 & 318 & Yes & 418 \\
\hline 3 & 40 & Male & $12-08-2010$ & 44 & Yes & 152 \\
\hline 4 & 41 & Female & $04-22-2010$ & 1 & Yes* & 682 \\
\hline 5 & 25 & Male & $12-23-2011$ & 261 & Yes & N/A \\
\hline 6 & 44 & Male & 06-01-2006 & 238 & Yes* & 185 \\
\hline 7 & 34 & Female & $11-29-2005$ & 370 & Yes & 625 \\
\hline 8 & 46 & Female & N/A & 487 & No & - \\
\hline 9 & 41 & Female & 04-24-2010 & 842 & No & 1138 \\
\hline
\end{tabular}

Note: Denotes those on second line antiretroviral therapy.

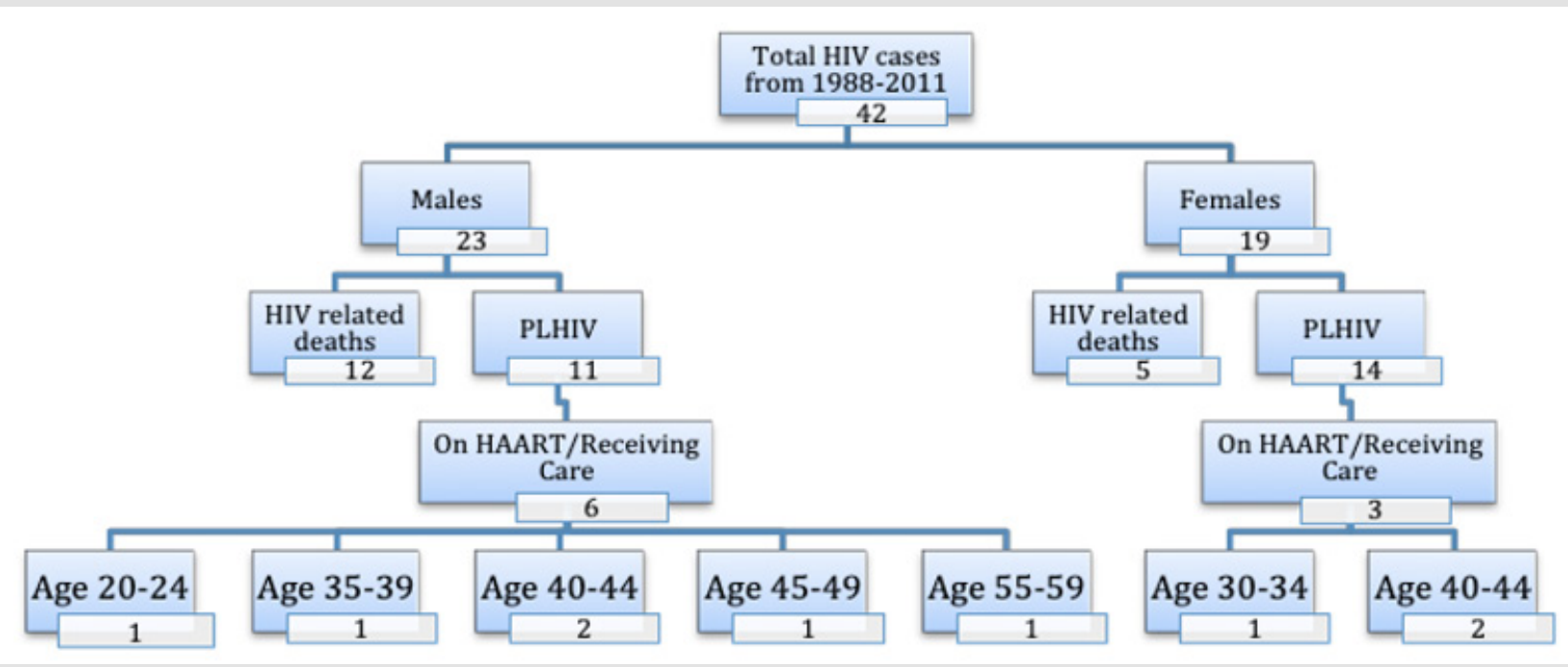

Figure 4: Summation of data for HIV cases from 1988-2011. 


\section{Mortality Trends}

During the period between 1988 and 2011, there were 17 $(42.5 \%)$ reported deaths among those individuals diagnosed with HIV. Of the 17 individuals who died, 12 (70.5\%) were males and $5(29.5 \%)$ were females. There was an additional death recorded in 2011, through the mortality coding system and not through the surveillance system. Therefore, the total number of deaths from 1988 until December 31, 2011, was 18 deaths. In addition, 20 individuals were believed to be alive and 5 persons were of unknown status by the end of 2011. Figures 5 and 6 illustrate the annual mortality trends for males and females, respectively, from 1988 until December 31, 2011.

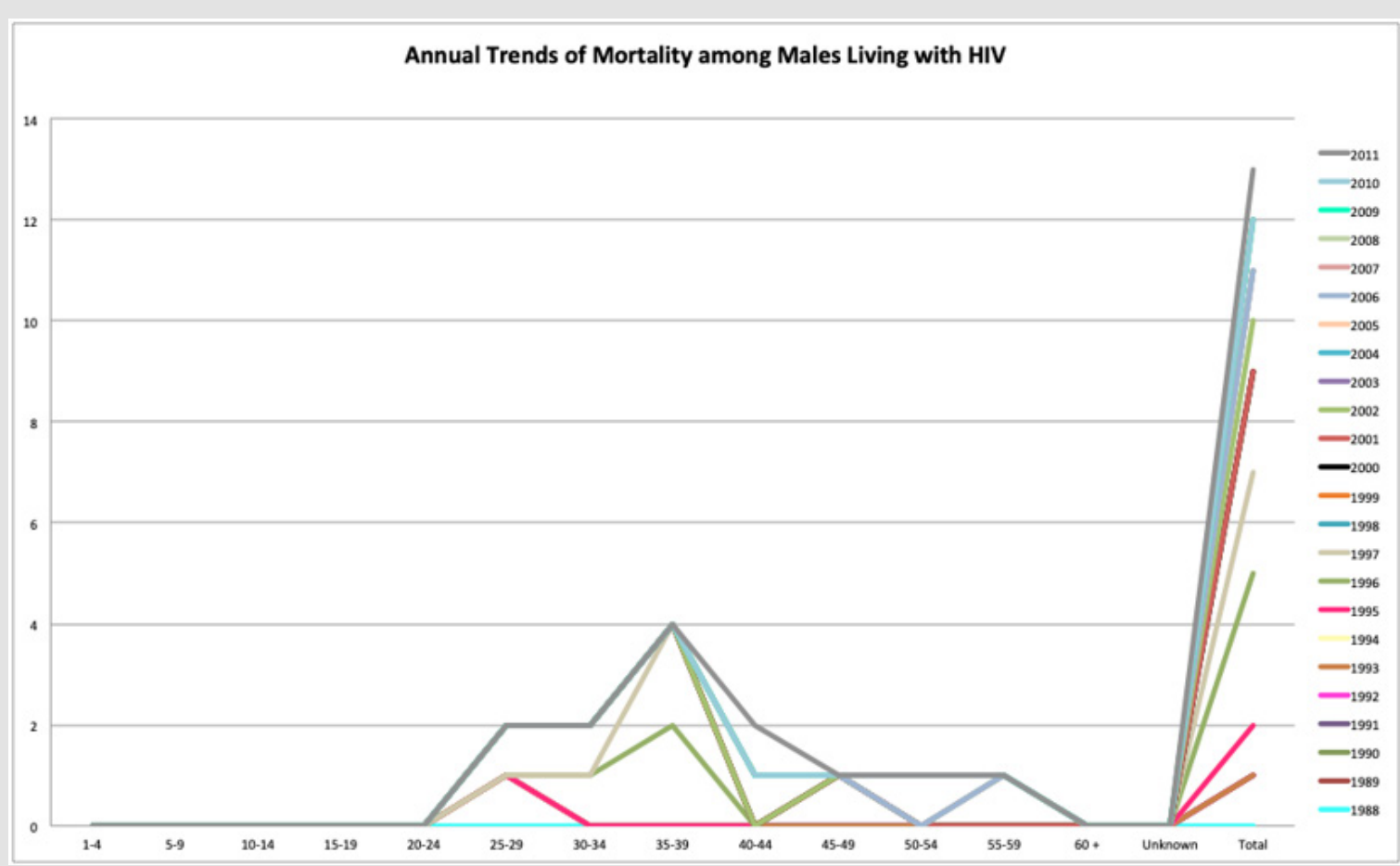

Figure 5: Mortality trends for males living with HIV from 1988 to 2011.

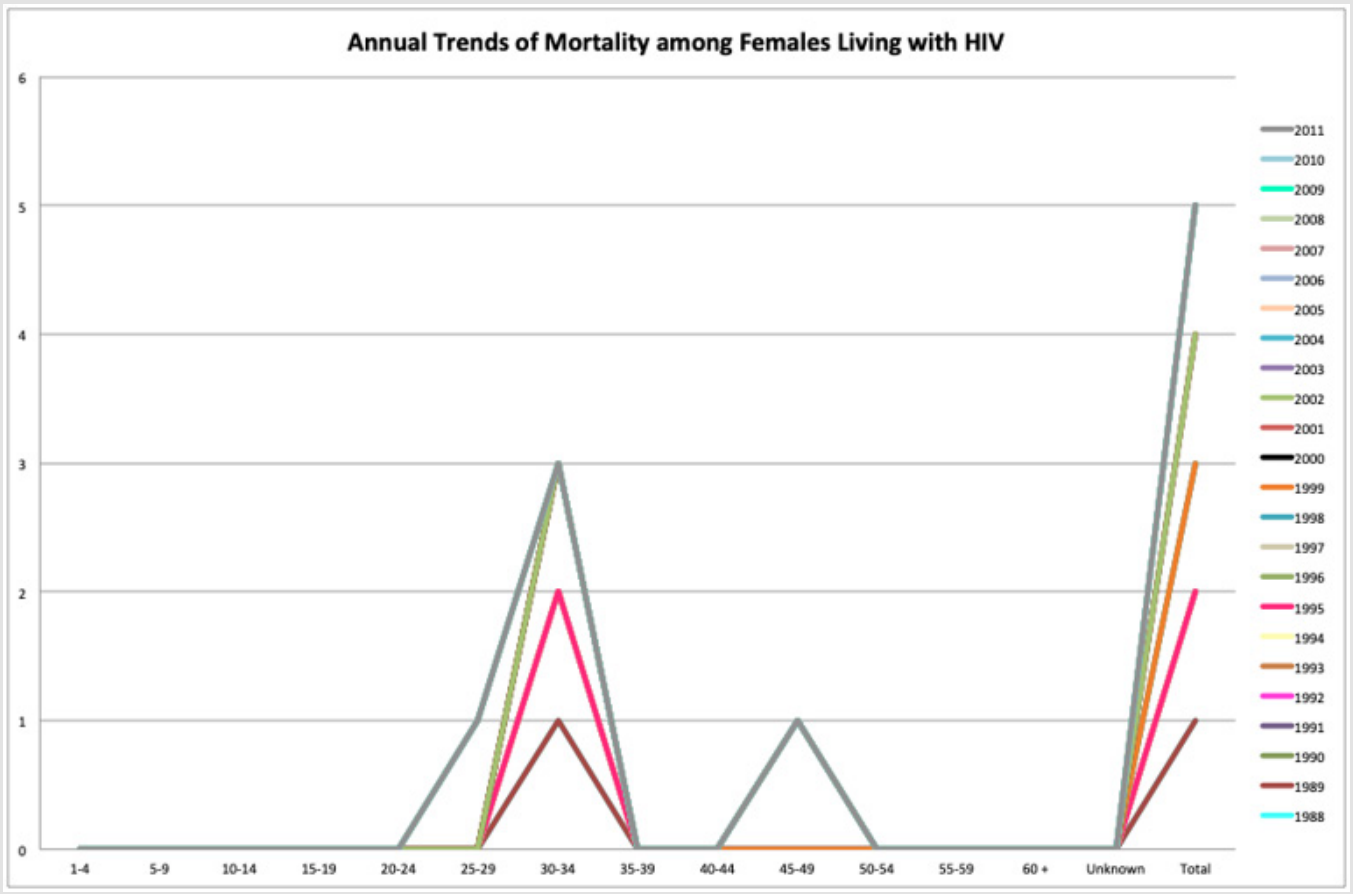

Figure 6: Mortality trends for females living with HIV from 1988 to 2011. 


\section{Discussion}

The first diagnosed case of HIV in Anguilla was in 1988, and up until 2011, 42 people have tested positive for the virus. The prevalence of HIV in Anguilla in 2011 was estimated to be $0.19 \%$, compared to the overall Caribbean prevalence of $1.6 \%$ in 2007 [4] and $1.2 \%$ in 2018 [2]. In 2005, the prevalence of HIV was $0.6 \%$ in North America and $0.5 \%$ in Latin America [1]. Females have a higher prevalence rate of HIV than males in Anguilla, 0.21\% and $0.17 \%$ respectively, and can be seen in Table 2 . Of the total number of patients that tested positive for HIV in Anguilla, 54.8\% were male and $45.2 \%$ were female. The epidemic is also growing among women in the Caribbean in general, with the percentage of cases in women increasing from $24 \%$ in 1990 to $43 \%$ in 2007 [1]. Between 1988 and 2011, 17 out of the 42 patients diagnosed with HIV in Anguilla were reported dead (12 males and 5 females). Of the 42 patients diagnosed with HIV in Anguilla, no case ever progressed to AIDS. Whereas, in Haiti, patients progress to AIDS after 5.2 years and die after 7.4 years [1]. Research shows that in Trinidad, HIV progresses to AIDS in a matter of 4.8 years after infection and death in 5.6 years [1]. In Anguilla, in 2011, there was one case of HIVrelated death.

A variety of testing routes were used from 1988 to 2011 to collect HIV information in Anguilla, such as voluntary, blood, routine antenatal visit screening, needle stick injuries and provider initiated testing. These results were provided to the Health Information Unit of the Ministry of Health in Anguilla every month, where they were analyzed and included in the annual statistical report. In 2011, 901 HIV tests were done (446 on males and 455 on females) in Anguilla, out of which 2 patients (2.2\%) tested positive for HIV with a 1:1 ratio for males and females. Different approaches are being taken to increase testing in the Caribbean and also to help increase awareness for diagnosis. HIV self-tests are not available in Anguilla; however, countries such as the Bahamas, Jamaica, Trinidad and Tobago, Brazil and El Salvador do provide such tests for their citizens [2]. Jamaica, Dominica, and Mexico, for example, offer HIV testing at local community centers by trained workers, rather than health care providers in clinics or hospitals, which provides more access for people [2]. All Caribbean countries, including Anguilla, screened $100 \%$ of blood products using a quality assured manner in 2006 and 2007, apart from Grenada and Antigua [3].

Although HIV testing is available throughout the Caribbean, it is not readily available and accessible to everyone. Most governments are yet to properly document HIV testing data or provide testing at reasonable costs [2]. There are obstacles facing the ability to test as many patients as possible, due to the fact that majority of the testing centers are located in larger cities, making it difficult for non-urban community dwellers to get tests done or to go for follow-up [2]. Another difficulty observed is that not all healthcare workers get proper training or some countries do not collect data on transgender women or female sex workers, leading to obstruction of testing amongst this population [2]. The Indian government lifted a ban on the use of media in 1993 for HIV information, and in 1994 the first advertisement for free condoms came out, resulting in a decline of HIV in sex workers due to condom use [7]. Incidence of HIV positive cases is declining in Asian countries, such as India with a $50 \%$ decline in incidence and China a 66\% decline, due to the government stepping in to raise awareness, education, and prevention [7]. Late diagnosis of HIV is a substantial issue in the Caribbean with over one-third of people having a CD4 count under 200 cells per $\mathrm{mm}^{3}$ [2]. Currently, due to the stigma and illegality of sex work, there is no information regarding commercial sex work in Anguilla or any information regarding injection drug use. Injection drug use is not a common mode of transmission of HIV in the Caribbean, except in Puerto Rico and Bermuda [1]. A high percentage of people in the Caribbean have negative misconceptions and bear malice toward patients living with HIV [3]. For instance, in Jamaica, 71\% of the population said they refuse to buy fresh produce from vendors who are HIV positive, as 58\% from Haiti and 49\% from the Dominican Republic [3].

The only countries in the Caribbean currently providing preexposure prophylaxis for HIV are the Bahamas and Barbados [3]. Most countries, including Anguilla, provide sexual education in primary and secondary schools; however, Haiti is one of the few countries that do not provide sexual education [3]. HIV awareness is highest in Cuba, where $76 \%$ of young women and $80 \%$ of young men have knowledge about HIV and ways to prevent it, compared to only 40 to $50 \%$ in the rest of the Caribbean [2]. A comprehensive program available in Jamaica has reduced the number of sexually transmitted infections (STIs) in the country [5], and the Dominican Republic has a similar program which has led to the prevention of many infections in female sex workers [1]. The Caribbean countries need to have a continued dedication to preventative methods that will include all the different groups of people in the population, so as to ensure continued reduction in the incidence of HIV viral infection [2]. A primary preventative method used by many countries is giving out free condoms to the young and those in need [2]. Anguilla is one of the 7 Caribbean countries that have eliminated mother-to-child transmission of HIV [2]. There was one case of vertical transmission of HIV reported in Anguilla in 1989 and only two HIV positive women gave birth between 1988 and 2011. In 2018, 1,000 infants were diagnosed with HIV in the entire Caribbean region [2].

There were 8,000 HIV positive women in the Caribbean who gave birth in 2018 [3]. In 2014, a study was performed on pregnant women in Ghana to show the relationship between education and HIV incidence [8]. The study showed an association of a higher incidence of HIV in the lower socioeconomic and less educated class [8]. However, the HIV prevalence in the general Ghanaian population is $1.9 \%$, with $2.9 \%$ in the Ghanaian pregnant class; hence, suggesting a need for more education [8]. Access to ARVT 
across the Caribbean is uneven and far behind many other regions. Treatment coverage is $61 \%$ of all people and $57 \%$ in the Caribbean [2]. Currently, $57 \%$ of adults who are HIV positive are receiving ARVT in the Caribbean [2]. About 181,000 people in the Caribbean were being treated in 2017 [3]. While in Anguilla, in 2011, 7 people (5 males and 2 females) received ARVT. Another hurdle is the affordability and availability of HIV medications. In some countries of Asia such as India, China, Thailand and Cambodia, only $47 \%$ of HIV positive patients have access to their required medications [7]. Currently, private practices in Anguilla do not have to report HIV to authorities making it problematic to obtain the complete picture of Anguilla's HIV epidemiology profile. Also, some people who suspect that they may have been infected may prefer to go for testing in the nearby Islands, such as St. Martin or St. Kitts and Nevis, for fear of being identified and subsequently being stigmatized by those who know them. Methods are needed to expand testing and awareness for everyone, but especially key populations due to the significantly higher concentrations of HIV [2].

\section{Conclusion}

The data provided in this epidemiological surveillance of HIV in Anguilla shows a gradual decline in the incidence of HIV infection in Anguilla since the first diagnosis was made in 1988. While various testing methods have helped to increase the awareness of HIV and its diagnosis, surveillance plays a fundamental role in public health and was a critical factor in the prevention and treatment strategies used in reducing the number of new infections and AIDS-related deaths. Hence, it is critically important to maintain a robust surveillance system despite the low numbers of the Anguillan population in order to stay abreast of the HIV situation. HIV surveillance systems monitor the magnitude and trends in the prevalence of HIV infection. Data from HIV surveillance systems are used for evidence-based decision making and program planning. Although Anguilla has successfully eradicated maternal vertical transmission of HIV infection, imperative efforts are required to make pre-exposure prophylaxis and ARVT medication accessible to people who need them in a continuous effort to mitigate the burden of the disease.

\section{ISSN: 2574-1241}

DOI: $10.26717 /$ BJSTR.2020.25.004238

Adekunle Sanyaolu. Biomed J Sci \& Tech Res

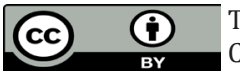

This work is licensed under Creative Commons Attribution 4.0 License

Submission Link: https://biomedres.us/submit-manuscript.php

\section{Acknowledgement}

We hereby wish to acknowledge the following people that contributed to the success of this project:

a. Ms. Shana Burrowes, Data Analyst, HIV/AIDS Programme, Ministry of Health, Barbados

b. Dr Clyde Bryan, Clinical Care Coordinator, Atlantic Star Medical Center, Anguilla

c. Ministry of Health Anguilla

d. Mrs. Celia Brooks, Health Information Coordinator, Anguilla

e. Pathology Department (PAH), Health Authority of Anguilla

f. National AIDS Programme, CAREC, Trinidad and Tobago

g. Dr. Bonnie Richardson-Lake, Permanent Secretary, Ministry of Health and Social Development

\section{References}

1. Pape JW (2016) HIV Disease in the Caribbean. Topics in Antiviral Medicine 19(1): e1-e5.

2. (2019) HIV and AIDS in Latin America and the Caribbean Regional Overview. Avert.

3. (2018) UNAIDS, Miles to Go: The response to HIV in the Caribbean. Global AIDS Update 2018.

4. (2006) UNAIDS, Global AIDS Review. World Health Organization.

5. Figueroa (2008) The HIV epidemic in the Caribbean: Meeting the challenges of achieving universal access to prevention, treatment and care. West Indian Medical Journal 57(3): 195-203.

6. (2007) UNAIDS, Caribbean AIDS epidemic update Regional Summary. World Health Organization.

7. Sanyaolu A, Okorie C, Kumar A, La Moure D, Rabadi M, et al. (2018) Current trends of HIV/AIDS in Asia. South East Asia Journal of Public Health 7(2): 3-11.

8. Orish VN, Onyeabor OS, Boampong JN, Afoakwah R, Nwaefuna E, et al. (2014) Influence of Education on HIV Infection among Pregnant Women Attending their Antenatal Care in Sekondi-Takoradi Metropolis, Ghana. Journal of Health Care for the Poor and Underserved 25(3): 982-990.

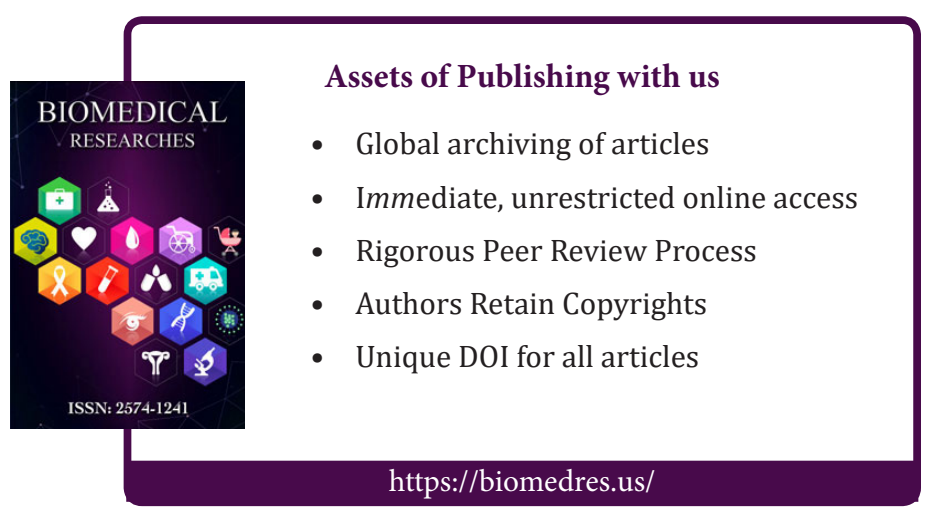

Copyright@ Adekunle Sanyaolu | Biomed J Sci \& Tech Res | BJSTR. MS.ID.004238. 